\title{
The effect of Enterococcus faecium M74 feed additive on the extended-spectrum beta-lactamases/AmpC-positive Escherichia coli faecal counts in pre-weaned dairy calves
}

\author{
Jana Šmídková ${ }^{1,2}$, Alois Č́ižek ${ }^{1}$ \\ University of Veterinary and Pharmaceutical Sciences Brno, Faculty of Veterinary Medicine, ${ }^{1}$ Institute of \\ Infectious Diseases and Microbiology, ${ }^{2}$ Ruminant and Swine Clinic, Brno, Czech Republic
}

Received May 31, 2017

Accepted December 19, 2017

\begin{abstract}
The increasing occurrence of extended-spectrum beta-lactamases and/or AmpC-positive Escherichia coli among different species of food producing animals poses a threat to public health. The animal gut plays a key role in the development of antibiotic resistant bacteria, allowing the selection, multiplication and subsequent contamination of the farm environment. However, applicable procedures for reducing such bacteria on farms are currently unavailable. The present study was aimed to determine whether a probiotic administration to new-born dairy calves would reduce faecal shedding of extended-spectrum beta-lactamases and/or AmpC-positive Escherichia coli during the pre-weaning period. Ten randomly assigned new-born Holstein calves on a dairy farm with recent evidence of high occurrence of AmpC-positive Escherichia coli among calves were treated by a probiotic mix within $12 \mathrm{~h}$ after birth. Nine control calves were not treated. Faecal samples were collected from each calf daily on days 2 through 5, and then on days 7, 10, and 14 . The faecal samples were cultured, and the mean numbers of cefotaxime-resistant Escherichia coli and confirmed enteroaggregative Escherichia coli were compared between the two groups. Results suggested that the Enterococcus faecium probiotic treatment (Enterococcus faecium M74, $N C I M B 11181$ ) of new-born calves did not reduce the enteroaggregative Escherichia coli counts in their faeces. There was no significant difference in the shedding of enteroaggregative Escherichia coli between the probiotic-treated and control calves throughout the two-week study period.
\end{abstract}

Probiotic, antimicrobial resistance, cattle

Continued increase in the incidence of antibiotic resistance among agents of infectious diseases of humans and animals represents a common threat to human and veterinary medicine. Along with pathogenic bacteria, antibiotic therapy also applies to commensal species of intestinal microflora, especially Escherichia coli, which can carry and then spread genes of resistance onto pathogenic species. That means that animal gut may play a key role in the development of antibiotic resistant bacteria, allowing the concealed selection, multiplication and subsequent contamination of the farm environment (Carlet 2012). The increasing incidence of extended-spectrum beta-lactamases (ESBL) and/or AmpC-positive Escherichia coli (enteroaggregative E. coli EAEC) in the community of the last decade is also connected with the findings of these bacteria in the food animals and their products (Seiffert et al. 2013). Therefore it seems reasonable to limit the use of antibiotics in farm animals to a minimum and look for procedures leading to the reduction of resistant bacteria on farms. The prevalence of ESBL in faecal swabs of healthy cattle in Europe is 5-13\% (Geser et al. 2012; Hartmann et al. 2012). The lowest prevalence of ESBL/AmpC-producing Escherichia coli in Europe is reported in Finland, at 1.8\% (Paivarinta et al. 2016). In the Czech Republic, data are available on the phenotypic resistance of Escherichia coli isolates in cattle for years $2015-10.7 \%$ and $2016-10.4 \%$ (SVA 2017). Results published so far show that in comparison to adult cattle, calves are relatively often colonized with resistant $E$. coli, including EAEC, although not treated with antibiotics (Khachatryan et al. 2004; Wats on et al. 2012). During the first weeks of milk

Address for correspondence:

Jana Šmídková

Ruminant and Swine Clinic, Faculty of Veterinary Medicine

University of Veterinary and Pharmaceutical Sciences

Phone: +420 777624044

Palackého tř. 1946/1, 61242 Brno, Czech Republic 
nutrition, the excretion reaches maximum level, and then gradually decreases with age (Khachatryan et al. 2004; Berge et al. 2005; Watson et al. 2012). Influences/factors that are involved in the selection and maintenance of these bacteria on dairy farms were also identified (Gonggrijp et al. 2016). But it is still not clear which extra measures will be effective to further reduce the prevalence of EAEC on dairy farms (Reeves et al. 2013). One of the options how to reduce the incidence of these bacteria on farms could be the induction of intestinal colonization resistance of new-born calves by using probiotics from the group of lactic acid bacteria (Signorini et al. 2012; Pringsulaka et al. 2015) which could reduce the excretion of EAEC in the calves' faeces. Only sporadic attempts to verify such procedures in order to reduce calf colonization by EAEC (Corbett et al. 2015) have been made so far.

The present study was aimed to determine whether a single administration of lactic acid bacteria to new-born dairy calves would reduce the faecal shedding EAEC.

\section{Materials and Methods}

Animals

The parent herd at the investigated farm consisted of 620 Holstein dairy cows with the average milk yield around 12000 litres per year. Cows were housed free in boxes with deep litter. The standard hygiene and mastitis prevention measures were implemented on the farm.

The born calves were immediately placed in individual boxes and fed with 41 of pasteurized colostrum within $2 \mathrm{~h}$. Further feeding consisted of two daily doses; the quality of colostrum was regularly checked. High percentage of faecal shedding of CMY-2 beta-lactamase producing $E$. coli in dairy calves during the pre-weaned period was proved during 2014.

Study design and sample collection

Ten randomly assigned new-born Holstein calves ( 5 heifers and 5 bulls) on the dairy farm with recent evidence of high occurrence of EAEC faecal shedding among pre-weaned calves were treated by a single dose of probiotic additive (Juvenor, Tekro with Enterococcus faecium M74, NCIMB 11181) administered per os within $12 \mathrm{~h}$ after birth according to the manufacturer's instructions. Nine control calves (6 heifers and 3 bulls) were not treated. Feeding and housing was as listed above.

Faecal samples were removed manually from the rectum into sterile plastic containers, changing gloves after each sample. Samples were collected from each calf daily on days 2 through 5 , and then on days 7,10 , and 14 . All samples were kept refrigerated and transported in an isothermal box to the laboratory, where they were processed.

Bacteriological methods

Faecal samples were weighed and initially diluted at a ratio of 1:10 in sterile phosphate-buffered saline (PBS) and homogenized by vortexing for $20 \mathrm{~s}$. A one millilitre aliquot of faecal suspension was serially diluted in PBS and selected dilutions were plated on MacConkey agar (Oxoid, UK) supplemented with $2 \mathrm{mg} / \mathrm{l}$ cefotaxime (Sigma, Czech Republic). All inoculated media were incubated overnight at $37{ }^{\circ} \mathrm{C}$. Lactose-fermenting colonies were enumerated and pure-cultured on MacConkey agar (Oxoid, UK) without antibiotics and on sheep blood agar plates (Oxoid, UK). Negative samples were enriched at $37^{\circ} \mathrm{C}$ for $16-18 \mathrm{~h}$ in MacConkey broth (Oxoid, UK) prior to plating as above and the positive finding was expressed as count $10^{1}$ colony forming units (CFUs) per gram of faeces. Pure presumptive cefotaxime-resistant isolates were identified using the matrix-assisted laser desorption ionization (MALDI)-time of flight (TOF) mass spectrometry (MALDI biotyper; Bruker Daltonics, USA) and confirmed Escherichia coli $(E$. coli) isolates further examined by ESBL/AmpC phenotype confirmatory tests $($ AmpC + ESBL Detection Set, Mast Group, UK) as we earlier described (Jamborova et al. 2015).

Statistical analysis

Analysis of variance (ANOVA) was used to compare the median of EAEC $\log 10 \mathrm{CFUs} / \mathrm{g}$ faeces in both the treated and control groups.

\section{Results}

During the investigated period all calves were clinically healthy and no treatment with antimicrobial drugs was used. A total of 115 samples from 19 study calves at 2 to 14 days of age were collected. The counts of EAEC for treated and control calves are summarized in Table 1. On day 2, EAEC was detected in all 7 sampled calves of the control group and in 7 out of 9 sampled calves of the treatment group. The mean EAEC count for faecal samples 
Table 1. Counts of ESBL/AmpC-positive Escherichia coli for treated and control calves (CFU/gram).

\begin{tabular}{ccccrcccc}
\hline \multicolumn{3}{l}{ Sampling } & \multicolumn{3}{c}{ Control group } & \multicolumn{3}{c}{ Treated group } \\
\hline Day & $\mathrm{n}$ & Mean & Median & Range & $\mathrm{n}$ & Mean & Median & Range \\
2 & 7 & $1.5 \cdot 10^{8}$ & $10^{5}$ & $10^{1}$ to $10^{9}$ & 9 & $9.3 \cdot 10^{8}$ & $10^{4}$ & 0 to $10^{9}$ \\
3 & 8 & $6.0 \cdot 10^{7}$ & $10^{6}$ & 0 to $10^{9}$ & 8 & $9.2 \cdot 10^{7}$ & $10^{5}$ & 0 to $10^{9}$ \\
4 & 8 & $5.1 \cdot 10^{8}$ & $10^{5}$ & 0 to $10^{9}$ & 7 & $4.2 \cdot 10^{8}$ & $10^{7}$ & $10^{5}$ to $10^{9}$ \\
5 & 9 & $5.4 \cdot 10^{8}$ & $10^{7}$ & 0 to $10^{9}$ & 9 & $5.1 \cdot 10^{8}$ & $10^{7}$ & $10^{1}$ to $10^{9}$ \\
7 & 8 & $2.1 \cdot 10^{8}$ & $10^{7}$ & $10^{1}$ to $10^{8}$ & 10 & $1.2 \cdot 10^{8}$ & $10^{7}$ & $10^{3}$ to $10^{9}$ \\
10 & 9 & $7.7 \cdot 10^{7}$ & $10^{7}$ & $10^{2}$ to $10^{8}$ & 9 & $2.5 \cdot 10^{8}$ & $10^{7}$ & $10^{1}$ to $10^{9}$ \\
14 & 7 & $1.5 \cdot 10^{7}$ & $10^{5}$ & $10^{1}$ to $10^{7}$ & 7 & $3.7 \cdot 10^{7}$ & $10^{6}$ & $10^{3}$ to $10^{8}$ \\
\hline
\end{tabular}

ESBL - extended-spectrum beta-lactamases; CFU - colony forming units; $n$ - number of sampled calves

collected on day 2 was $1.5 \cdot 10^{8} \mathrm{CFU} / \mathrm{g}$ (median, $10^{5} \mathrm{CFU} / \mathrm{g}$; range $10^{1}$ to $10^{9} \mathrm{CFU} / \mathrm{g}$ ) in the control calves and $9.3 \cdot 10^{8} \mathrm{CFU} / \mathrm{g}$ (median, $10^{4} \mathrm{CFU} / \mathrm{g}$; range 0 to $10^{9} \mathrm{CFU} / \mathrm{g}$ ) in the treated calves. Stabilization of the median value is apparent after 4 days of observation in documented EAEC counts in both groups of calves. Nevertheless, a relatively large gap in CFU of EAEC/gram of faeces counts was found in individual calves in both groups during the monitored days. Figure 1 represents the cumulative shedding dynamics of EAEC in both groups of calves. There is no apparent difference between cumulated CFU EAEC values with the exception of the first day of the testing. A noticeable drop in EAEC shedding was recorded at the end of the investigated period.

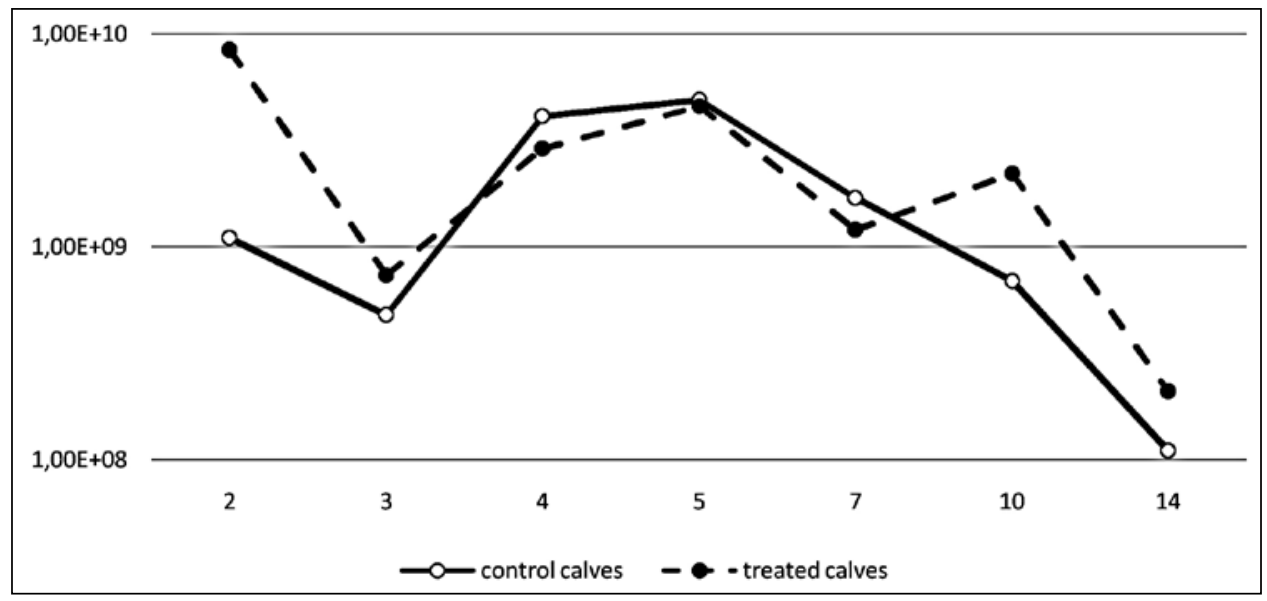

Fig. 1. The cumulative shedding of extended-spectrum beta-lactamases/AmpC-positive Escherichia coli in the treated calves $(n=10)$ and control calves $(n=9)$ (colony forming units per gram - CFUs/gram of faeces)

Daily faecal shedding of ESBL/AmpC-positive Escherichia coli in calves of treated and control groups is documented in Tables 2 and 3. Bold print indicates the ESBL-positive E. coli shedding in some calves; but most calves shed AmpC-positive E. coli in both groups.

Mean and median EAEC counts did not differ significantly between the treatment and control groups ( $P$ value was 0.93$)$. On the third day $P$ was 0.1 , which is still non-significant.

There was no significant difference in the shedding of EAEC between the probiotictreated and control calves throughout the two-week study period. 
Table 2. Daily faecal shedding of extended-spectrum beta-lactamases/AmpC-positive Escherichia coli for treated calves (CFU/gram).

\begin{tabular}{|c|c|c|c|c|c|c|c|}
\hline \multirow{2}{*}{ Calf } & \multicolumn{6}{|c|}{ Sampling days } & \multirow[b]{2}{*}{14} \\
\hline & 2 & 3 & 4 & 5 & 7 & 10 & \\
\hline JA & $2.3 \cdot 10^{2}$ & $10^{1}$ & $2.6 \cdot 10^{9}$ & $4.2 \cdot 10^{5}$ & $4.6 \cdot 10^{7}$ & $8.0 \cdot 10^{7}$ & $1.8 \cdot 10^{6}$ \\
\hline JB & $2.7 \cdot 10^{4}$ & $3.2 \cdot 10^{4}$ & $8.1 \cdot 10^{6}$ & $4.6 \cdot 10^{8}$ & $2.73 \cdot 10^{8}$ & $4.9 \cdot 10^{7}$ & $1.0 \cdot 10^{6}$ \\
\hline $\mathrm{JC}$ & $4.0 \cdot 10^{8}$ & $1.9 \cdot 10^{5}$ & $2.2 \cdot 10^{7}$ & $3.8 \cdot 10^{9}$ & $1.0 \cdot 10^{7}$ & $6.4 \cdot 10^{8}$ & $1.7 \cdot 10^{8}$ \\
\hline $\mathrm{JD}$ & $2.8 \cdot 10^{4}$ & $4.8 \cdot 10^{7}$ & $1.4 \cdot 10^{5}$ & NT & $1.6 \cdot 10^{8}$ & NT & NT \\
\hline $\mathrm{JE}$ & $4.0 \cdot 10^{8}$ & $5.7 \cdot 10^{8}$ & NT & $2.1 \cdot 10^{8}$ & $4.2 \cdot 10^{8}$ & $1.6 \cdot 10^{7}$ & $6.3 \cdot 10^{7}$ \\
\hline JF & $10^{1}$ & $5.2 \cdot 10^{4}$ & NT & $8.5 \cdot 10^{7}$ & $9.1 \cdot 10^{7}$ & $2.75 \cdot 10^{6}$ & $1.04 \cdot 10^{5}$ \\
\hline JG & 0 & 0 & NT & $6.7 \cdot 10^{7}$ & $2.3 \cdot 10^{3}$ & $1.46 \cdot 10^{7}$ & $2.2 \cdot 10^{7}$ \\
\hline $\mathrm{JH}$ & $1.2 \cdot 10^{9}$ & NT & $3.4 \cdot 10^{8}$ & $10^{1}$ & $1.46 \cdot 10^{7}$ & $1.39 \cdot 10^{9}$ & NT \\
\hline JI & 0 & NT & $1.0 \cdot 10^{6}$ & $5.0 \cdot 10^{4}$ & $1.4 \cdot 10^{8}$ & $1.39 \cdot 10^{7}$ & NT \\
\hline $\mathrm{JK}$ & NT & $1.2 \cdot 10^{8}$ & $2.6 \cdot 10^{7}$ & $7.0 \cdot 10^{6}$ & $2.0 \cdot 10^{7}$ & $8.1 \cdot 10^{6}$ & $9.0 \cdot 10^{3}$ \\
\hline
\end{tabular}

CFU - colony forming units; NT - not tested; ESBL - extended-spectrum beta-lactamases; 0 - negative result; bold print - ESBL-positive E. coli

Table 3. Daily faecal shedding of extended-spectrum beta-lactamases/AmpC-positive Escherichia coli for control calves (CFU/gram).

\begin{tabular}{|c|c|c|c|c|c|c|c|}
\hline \multirow{2}{*}{ Calf } & \multicolumn{6}{|c|}{ Sampling days } & \multirow[b]{2}{*}{14} \\
\hline & 2 & 3 & 4 & 5 & 7 & 10 & \\
\hline A & NT & $1.0 \cdot 10^{6}$ & $1.2 \cdot 10^{9}$ & $2.18 \cdot 10^{9}$ & $4.6 \cdot 10^{7}$ & $2.3 \cdot 10^{7}$ & $8.0 \cdot 10^{6}$ \\
\hline B & $10^{1}$ & 0 & 0 & 0 & NT & $1.71 \cdot 10^{8}$ & $5.0 \cdot 10^{5}$ \\
\hline $\mathrm{C}$ & $2.5 \cdot 10^{7}$ & $2.4 \cdot 10^{8}$ & $1.7 \cdot 10^{7}$ & $1.9 \cdot 10^{7}$ & $1.5 \cdot 10^{8}$ & $2.1 \cdot 10^{7}$ & $4.9 \cdot 10^{5}$ \\
\hline $\mathrm{D}$ & $1.4 \cdot 10^{7}$ & $1.0 \cdot 10^{7}$ & $2.5 \cdot 10^{7}$ & $8.1 \cdot 10^{7}$ & $8.0 \cdot 10^{8}$ & $4.5 \cdot 10^{7}$ & $10^{1}$ \\
\hline $\mathrm{E}$ & $4.0 \cdot 10^{5}$ & $2.2 \cdot 10^{8}$ & $1.41 \cdot 10^{5}$ & $5.4 \cdot 10^{7}$ & $8.3 \cdot 10^{7}$ & $9.0 \cdot 10^{3}$ & $1.7 \cdot 10^{5}$ \\
\hline $\mathrm{F}$ & $2.0 \cdot 10^{3}$ & 0 & NT & 0 & $7.6 \cdot 10^{7}$ & $3.0 \cdot 10^{6}$ & $9.7 \cdot 10^{7}$ \\
\hline G & $1.0 \cdot 10^{4}$ & NT & $7.9 \cdot 10^{4}$ & $1.28 \cdot 10^{8}$ & $9.6 \cdot 10^{7}$ & $4.3 \cdot 10^{8}$ & NT \\
\hline $\mathrm{H}$ & NT & $10^{1}$ & $2.5 \cdot 10^{4}$ & $3.3 \cdot 10^{4}$ & $10^{1}$ & $1.0 \cdot 10^{2}$ & $10^{1}$ \\
\hline I & $1.05 \cdot 10^{9}$ & 0 & $2.91 \cdot 10^{9}$ & $2.4 \cdot 10^{9}$ & $4.3 \cdot 10^{8}$ & $1.3 \cdot 10^{7}$ & NT \\
\hline
\end{tabular}

$\overline{\mathrm{CFU}}$ - colony forming units; NT - not tested; ESBL - extended-spectrum beta-lactamases; 0 - negative result; bold print - ESBL-positive E. coli

\section{Discussion}

Antimicrobial resistance is considered to be a major health threat for humans. Resistance can be partly caused by transmission of resistant bacteria from livestock, directly or through the contaminated environment and foodstuffs (Seiffert et al. 2013). Reducing EAEC prevalence in livestock is expected to contribute to decreasing the health risks for humans and improve the animals' health status in general.

Currently, it is still not clear which extra measures will be effective to further reduce the prevalence of EAEC in dairy cattle herds. The lack of scientific information complicates evaluating the epidemiological effectiveness of possible measures and the associated costs. Due to the high prevalence of antibiotic-resistant $E$. coli in pre-weaned dairy calves during the first weeks of life, it seems appropriate to authenticate probiotics to enhance the intestinal colonization resistance of calves against EAEC. The probiotic properties of the lactic acid bacteria, especially those of Enterococcus faecium, are widely employed in 
feed additives for various domestic animals. Lactic acid bacteria, especially Enterococcus faecium decreased excretion of enterohemorrhagic Escherichia coli $\mathrm{O} 157: \mathrm{H} 7$ in lambs (Lema et al. 2001). The probiotic strain Enterococcus faecium M74, NCIMB 11181 was also used in our study based on this data. The results evaluating the effect of this probiotic on the excretion of E.coli in calves are missing in literature. The Enterococcus faecium M74, NCIMB 11181 strain is a feed additive authorised in the category of "zootechnical additives", functional group "gut flora stabilizers" according to Annex I of Regulation (EU) No 1831/2003. It plays a major role among the known strains of lactic acid producing bacteria in animal nutrition. This strain is characterized by the development of its metabolic activity in the intestine, the release of antimicrobial substances, and formation of a biofilm to protect the intestinal mucosa.

In our study, we were unable to prove a decreased excretion of EAEC in calves treated with a single dose of this product after birth. Our results are comparable with the recent results of Corbett et al. (2015) who also found that probiotic administration in pre-weaned calves did not reduce antimicrobial-resistant coliform count in their faeces. In contrast to our study, these authors used a commercial product based on multi-strain probiotics consisting of representatives of the genes Bacillus, Lactobacillus, and Bifidobacterium. In the critical evaluation of our own results and the results of Corbett et al. (2015), it needs to be stated that commercial probiotic products are used for a number of benefits and the evaluation of antimicrobial activity in the selection of probiotic strains does not have to be considered.

In commercial products the request of the same probiotic strain origin with the target species for which it is intended is also usually not respected. These shortcomings might have had a negative impact on the outcome of this study. The antimicrobial effects of probiotics are strain-dependent, therefore we assume that it will be necessary and useful to isolate probiotic bacteria directly from cattle and perform a screening for the exhibition of anti-EAEC activity in the future. Mono- or multi-strain probiotics with anti-EAEC activity may be used as a complement to reduce the prevalence of ESBLs/AmpC positive E. coli in the future, possibly strengthening the preventative animal health management and the biosecurity of the farm.

\section{Acknowledgement}

The study was supported by the project IGA 102/2014/FVL.

\section{References}

Berge AC, Atwill ER, Sischo WM 2005: Animal and farm influences on the dynamics of antibiotic resistance in faecal Escherichia coli in young dairy calves. Prev Vet Med 69: 25-38

Busing K, Zeyner A 2014: Effects of oral Enterococcus faecium strain DSM 10663 NCIMB 10415 on diarrhea patterns and performance of sucking piglets. Benef Microbes 6: 41-44

Carlet J 2012: The gut is the epicentre of antibiotic resistance. Antimicrob Resist In 1: 39

Corbett EM, Norby B, Halbert LW, Henderson ST, Grooms DL, Manning SD, Kaneene JB 2015: Effect of feeding a direct-fed microbial on total and antimicrobial-resistant fecal coliform counts in preweaned dairy calves. Am J Vet Res 76: 780-788

Gonggrijp MA, Santman-Berends IM, Heuvelink AE, Buter GJ, van Schaik G, Hage JJ, Lam TJ 2016: Prevalence and risk factors for extended-spectrum $\beta$-lactamase- and AmpC-producing Escherichia coli in dairy farms. J Dairy Sci 99: 9001-9013

Geser N, Stephan R, Hächler H 2012: Occurrence and characteristics of extended-spectrum $\beta$ - lactamase (ESBL) producing Enterobacteriaceae in food producing animals, minced meat and raw milk. BMC Vet Res 8: 21

Hartmann A, Locatelli A, Amoureux L, Depret G, Jolivet C, Gueneau E, Neuwirth C 2012. Occurrence of CTX-M producing Escherichia coli in soils, cattle, and farm environment in france (Burgundy region). Front Microbiol 3: 83

Hordijk J, Mevius DJ, Kant A, Bos ME, Graveland H, Bosman AB, Hartskeerl CM, Heederik DJJ, Wagenaar JA 2013: Within-farm dynamics of ESBL/AmpC-producing Escherichia coli in veal calves: a longitudinal approach. J Antimicrob Chemoth 68: 11 
Hordijk J, Wagenaar JA, van de Giessen A, Dierikx C, van Essen-Zandbergen A, Veldeman K, Kant A, Mevius D 2013: Increasing prevalence and diversity of ESBL/AmpC-type- $\beta$-lactamase genes in Escherichia coli isolated from veal calves from 1997 to 2010. J Antimicrob Chemoth 68: 1970-1973

Jamborova I, Dolejska M, Vojtech J, Guenther S, Uricariu R, Drozdowska J, Papousek I, Pasekova K, Meissner W, Hordowski J, Cizek A, Literak I 2015: Plasmid-mediated resistance to cephalosporins and fluoroquinolones in various Escherichia coli sequence types isolated from rooks wintering in Europe. Appl Environ Microbiol 81: $648-657$

Khachatryan AR, Hancock DD, Besser TE, Call DR 2004: Role of calf-adapted Escherichia coli in maintenance of antimicrobial drug resistance in dairy calves. Appl Environ Microbiol 70: 752-757

Lema M, Williams L, Rao DR 2001: Reduction of fecal shedding of enterohemorrhagic Escherichia coli O157:H7 in lambs by feeding microbial feed supplement. Small Ruminant Res 39: 31-39

Paivarinta M, Pohloja L, Fredriksson-Ahomaa M, Heikinheimo A 2016: Low cccurrence of extended-spectrum b-lactamase-producing Escherichia coli in Finnish food-producing animals. 2016 Blackwell Verlag GmbH, Zoonoses and Public Health 63: 624-631

Pringsulaka O, Rueangyotchanthana K, Suwannasai N, Watanapokasin R, Amnueysit P, Sunthornthummas S, Sukkhum S, Sarawaneeyaruk S, Rangsiruji A 2015: In vitro sreening of lactic acid bacteria for multi-strain probiotics. Livest Sci 174: 66-73

Pajarillo EAB, Chae JP, Balolong MP, Kim HB, Park CS, Kang DK 2015: Effects of probiotic Enterococcus faecium NCIMB 11181 administration on swine fecal microbiota diversity and composition using barcoded pyrosequencing. Anim Feed Sci Tech 201: 80-88

Reeves HE, Lotz SB, Kennedy E, Randall LP, Coldham NG, La Ragione RM 2013: Evaluation of an autogenous vaccine in cattle against Escherichia coli bearing the CTX-M-14 plasmid. Res Vet Sci 94: 419-424

Reg (EC) No 1831/2003. European Union Register of Feed Additives. Edition 250. Appendixes 3e, $4-24.01 .2017$ European Union legislation on feed additives. Available at: http://ec.europa.eu/food/safety/animal-feed/feedadditives/index en.htm

Seiffert SN, Hilty M, Perreten V, Endimiani A 2013: Extended-spectrum cephalosporin-resistant gram-negative organisms in livestock: An emerging problem for human health? Drug Resist Update 16: 22-45

Signorini ML, Soto LP, Zbrun MV, Sequeira GJ, Rosmini MR, Frizzo LS 2012: Impact of probiotic administration on the health and fecal microbiota of young calves: a meta-analysis of randomized controlled trials of lactic acid bacteria. Res Vet Sci 93: 250-258

Snow LC, Warner RG, Cheney T, Wearing H, Stokes M, Harris K, Teale CJ, Coldham NG 2012: Risk factors associated with extended spectrum beta-lactamase Escherichia coli (CTX-M) on dairy farms in North West England and North Wales. Prev Vet Med 106: 225-234

State Veterinary Administration 2017: National Program for Monitoring of Antimicrobial Resistance in Important Veterinary Pathogens. Newsletter 4: 23

Watson E, Jeckel S, Snow L, Stubbs R, Teale C, Wearing H, Horton R, Toszeghy M, Tearne O, Ellis-Iversen J, Coldham N 2012: Epidemiology of extended spectrum beta-lactamase E. coli (CTX-M-15) on a commercial dairy farm. Vet Microbiol 154 : 339-346 